Bangl. J. Vet. Med. (2007). 5 (1 \& 2): 107-110

\title{
EFFECTS OF EDIBLE FATS AND OILS ON THE BODY WEIGHT GAIN AND ON WEIGHTS OF SOME SELECTED ORGANS IN RATS REMOVING THE IMPACT OF UNEQUAL FEED INTAKE
}

\author{
N. Ahmad, S. Majumder ${ }^{1}$, M. A. Miah and M. J. Uddin \\ Department of Physiology, ${ }^{1}$ Department of Agricultural Statistics, Faculty of Veterinary Science, Bangladesh \\ Agricultural University, Mymensingh-2202, Bangladesh \\ Corresponding author’s e-mail address: smagstabau@yahoo.com
}

\begin{abstract}
An investigation on Long Evans male rats fed with different edible fats and oils was conducted in the Department of Physiology, Bangladesh Agricultural University, Mymensingh during a period of 7 weeks $\left(1^{\text {st }}\right.$ April to $19^{\text {th }}$ May, 2005) to determine and to compare the effect of feeds on body weight gain and on weights of some selected organs (heart, liver and kidney) removing the impact of unequal feed intake. A total of 20, six-week old male rats were randomly divided into A, B, C and D groups. Each group consisted of 5 rats. Rats were fed rat pellets purchased from ICDDR,B, Dhaka supplemented with beef fat in group A, fish fat in group B and soybean oil in group C while group D was considered as control and fed only with rat pellets. The concentration of fats and oils were $7 \%$ of normal diet and fed for 7 weeks. The highest weekly mean body weight gain (19.90g) adjusted for unequal feed intake was achieved by the rats of beef fat supplemented group A, followed by the rats of soybean oil supplemented group C (19.76g) and fish fat supplemented group B (15.67g). But none of the adjusted means of weekly body weight gain differed significantly $(p>0.05)$ from the control. Insignificant increases in heart weight were recorded in all treated rats and the maximum weight was in fish oil treated ones. Not much differences were recorded in the kidney weights rather beef oil treated rats' kidney had the lowest mean weight. A significantly $(\mathrm{p}<0.01)$ higher liver weight was recorded in group B \& C compared to control (group D), though the differences between A \& D were insignificant. It could be concluded that fats and oils are harmful for the rat's body especially on liver and heart.
\end{abstract}

Key words: Edible fats and oils, rat, body weight, organ weight, analysis of variance, covariance

\section{INTRODUCTION}

Fats and oils play an important role to supply high energy and are also important for the taste and desirable flavor of the food. Each gram of oil or fat supplies 9 Kcal energy which is the double of the quantity of energy as is provided by protein or carbohydrate. Fats and oils are also the sources of essential fatty acids. They also act as carrier of fat-soluble vitamins (A, D, E and K) in the body. Fats and oils are essential to synthesize phospholipids which are important component of active tissue like brain, nerve and liver. Despite the necessities of fats and oils, the long term use of them can cause complications in the body. High fats and oils intake with diet causes atherosclerosis, ischemic heart disease, chronic nephritis, etc. Fats and oils which contain more unsaturated fatty acids are particularly susceptible to oxidation. The intake of food containing oxidized lipid increase the concentration of secondary peroxidation products in the liver. Metabolism of these components ultimately affects the activity of different lipogenic enzymes and causes various types of liver injury (Slater, 1972).

Dietary fats and oils chiefly composed of fatty acids and cholesterol. Large amount of cholesterol partially inhibit endogenous cholesterol synthesis but result in a net increase in serum cholesterol concentrations because of suppression of synthesis of LDL (low density lipoprotein) receptor. Current recommendations are to limit dietary fat and cholesterol consumption to $30 \%$ or less of total calories and $300 \mathrm{mg}$ or less per day respectively (Baron and Browner, 1998). The cholesterol, saturated fatty acids and trans fatty acids of fats and oils increase the risk of coronary heart diseases by increasing the blood cholesterol (Lichtenstein, 1998). Unsaturated fatty acids decrease the level of cholesterol as well as increase the level of LDL. Different laboratory animals are used for human and animal disease models as well as to study the pathogenesis of various diseases. Hosain et al. (2004) conducted a laboratory experiment for identifying the effects of different edible oils on hematobiochemical profiles in rats. 
Saha et al. (2005) also performed an experiment in the laboratory to know the effects of different edible oils on growth performance, different organ weight and serum transaminases in rats. But they did not consider feed intake data in their study by subtracting wastage from the supplied amount of feed. So, we think that comparison among the feed groups would have had more validity if feed intake data were used. In the present study, we have made an attempt to collect feed intake data for determining and comparing the effects of edible fats (beef fat and fish fat) and oils (soybean oil) in laboratory animals in Bangladesh. Usually feed intake data of the different feed groups are not equal. So, an experiment has been undertaken to identify and to compare the effects of different edible fats and oils on the body weight gain and on weights of some selected organs in rats removing the impact of unequal feed intake.

\section{MATERIALS AND METHODS}

A total of 20, six-week old male Long Evans rats purchased from ICDDR,B, Dhaka were used in the experiment conducted in the Department of Physiology, Bangladesh Agricultural University, Mymensingh during a period of 7 weeks $\left(1^{\text {st }}\right.$ April to $19^{\text {th }}$ May, 2005). The rats were randomly divided into four equal groups $(\mathrm{n}=5)$ and numbered as A, B, C and D. Groups A, B and C were treated respectively with beef fat, fish fat and soybean oil at a concentration of $7 \%$ with rat pellet for 7 weeks, while group D served as control. We decided to use 7\% extra fats and oils in rat pellet as the experiment of edible oils (viz., soybean oil, palm oil, coconut oil and mustard oil) at a concentration of $7.5 \%$ with rat pellet exhibited significant results on the growth performance and different organs' weight (Saha et al., 2005).

The feeds with edible fats and oils at a concentration of $7 \%$ were provided to the rats of treated groups up to seven weeks at the rate of $15 \mathrm{~g} /$ rat daily for $1^{\text {st }}$ week and $20 \mathrm{~g} /$ rat daily for subsequent days. Feeds without edible fats and oils at these rates were supplied to the rats of control group. Feed was supplied combinely to the rats of each group that compelled us to collect feed intake data aggregately for each group and hence the average amount of daily feed intake per rat in each group was obtained after subtracting wastage from the supplied amount and taking average of it. Initial body weight of each rat was measured with the help of an electric balance. Body weight was then taken after every seventh day until the last day of experiment. After 7 weeks, the weights of different organs (viz., heart, liver and kidney) were recorded by sacrificing the rats by cervical displacement.

\section{Statistical analyses}

The adjusted (for unequal feed intake) weekly mean body weight gains of the experimental rats of different groups were computed by performing analysis of covariance in randomized complete block design (Gomez and Gomez, 1984).

Since the weights of different organs were recorded once at the end of the experiment, thus the average feed intake per rat over the whole experimental period in each group can be incorporated in the analysis of covariance. But the average feed intake per rat in the groups over the whole experimental period was about the same and hence adjustment for unequal feed intake by analysis of covariance for organ weights was not made.

The equality of the means of organ weights of the rats fed with different edible fats and oils was tested by Fratio performing one-way analysis of variance (Gomez and Gomez, 1984). The mean body weight gains and organ weights of the different groups were compared with the control by Dunnett's test procedure (Steel and Torrie, 1980).

\section{RESULTS AND DISCUSSION}

There was no significant ( $p>0.05$ ) difference of the weekly mean body weight gain (adjusted for unequal feed intake) of rats of the various feed groups from the control (Table 1). Nevertheless, it can be stated that the highest weekly mean body weight gain was attained by the rats of group A (beef fat supplemented group) followed by the group C (soybean oil supplemented group) and the least for group B (fish fat supplemented group). It is apparent from Table 1 that the highest and lowest mean body weight gain were obtained for the rats of group C and D respectively before removing the impact of unequal feed intake. So, adjustment in body weight gain was very essential due to unequal feed intake. The adjustment accomplishes two important improvements: (i) The mean body weight gain is adjusted to a value that it would have had if there were no difference in the amounts of feed intake of the groups and (ii) The experimental error is reduced \& the precision for comparing mean body weight gain of the different groups is increased. 
Impact of unequal feed intake on body weight of rats

Table 1. Computation of the adjusted weekly mean body weight gain of each feed group and their comparison with the control

\begin{tabular}{|c|c|c|c|c|c|c|c|}
\hline $\begin{array}{l}\text { Feed } \\
\text { groups }\end{array}$ & $\begin{array}{l}\text { Unadjusted } \\
\text { weekly } \\
\text { mean body } \\
\text { weight } \\
\text { gain, } \\
\bar{Y}_{i}(\mathrm{~g})\end{array}$ & $\begin{array}{l}\text { Mean feed } \\
\text { intake per } \\
\text { day, } \bar{X}_{i}(\mathrm{~g})\end{array}$ & $\begin{array}{l}\text { Deviation } \\
D=\bar{X}_{i}-\bar{X}\end{array}$ & $\begin{array}{l}\text { Adjusted } \\
\text { factor for } \\
\text { unequal feed } \\
\text { intake, } \\
\text { C = BD }\end{array}$ & $\begin{array}{l}\text { Adjusted } \\
\text { weekly mean } \\
\text { body weight } \\
\text { gain } \\
\bar{Y}_{i}^{\prime}=\overline{Y_{i}}-C\end{array}$ & $\begin{array}{l}\text { Standard } \\
\text { error } \\
(\mathrm{SE}) \text { for } \\
\bar{Y}_{i}^{\prime}\end{array}$ & SED \\
\hline A & 17.897 & 17.033 & -0.2232 & -2.0056 & $19.90^{\mathrm{a}}$ & 1.757 & 1.05 \\
\hline B & 18.249 & 17.543 & 0.2868 & 2.5771 & $15.67^{\mathrm{a}}$ & 1.917 & 1.10 \\
\hline C & 20.140 & 17.299 & 0.0425 & 0.3819 & $19.76^{\mathrm{a}}$ & 1.488 & 0.96 \\
\hline $\begin{array}{l}\text { D } \\
\text { (Control) }\end{array}$ & 16.329 & 17.150 & -0.1061 & -0.9534 & 17.28 & 1.544 & - \\
\hline
\end{tabular}

Superscript ' $a$ ' of the column six indicates insignificant $(\mathrm{p}>0.05)$ difference of an adjusted mean from the control, $A=$ Normal Feed $(N F)+$ Beef fat, $B=N F+$ Fish fat, $C=N F+$ Soybean oil, $D=N F, S E D=$ Standard error of the mean difference, $\bar{X}=$ Grand mean $=17.2561 \mathrm{~g}$.

Like the present study various investigations have been performed on rats (Gaiva et al., 2003; Al-Othman, 2000; Rashid et al., 1998) to find out the effects of fish oil, soybean oil and ghee on body weight gain. The concentration of fats and oils, and duration of experiment were variable. They recorded increased but variable and inconsistent body and organ weight. About $2 \%$ soybean meal resulted increased body weight gain in broiler (Islam et al., 2002; Barek et al., 2003) while in the present study soybean oil became the second category when compared with beef fat and fish oil in rats. In white Roman geese (Li et al., 1996), beef fat caused highest body weight gain than dalda and palm oil, and hilsa fish oil. The findings of Li et al. (1996) in white Roman geese corresponded with findings of the present investigation where beef fat got the top priority than the soybean and fish oil in rats. Saha et al. (2005) observed that there existed a significant difference among the effects of different edible oils on the growth performance. But the validity of this result can not be considered as much as our present one because they did not remove the impact of the unequal feed intake.

Table 2. Comparison of organ weights ${ }^{\mathrm{b}}$ of the different feed groups with the control

\begin{tabular}{|lllll|}
\hline Name of organs & Group A & Group B & Group C & Group D (Control) \\
\hline Heart (g) & $0.96 \pm 0.07$ & $1.10 \pm 0.11$ & $0.92 \pm 0.07$ & $0.84 \pm 0.07$ \\
Liver (g) & $7.66 \pm 0.26$ & ${ }^{* *} 9.52 \pm 0.41$ & ${ }^{* *} 9.84 \pm 0.44$ & $7.64 \pm 0.33$ \\
Kidney (g) & $1.28 \pm 0.02$ & $1.40 \pm 0.10$ & $1.52 \pm 0.11$ & $1.40 \pm 0.08$ \\
\hline
\end{tabular}

${ }^{* *}$ Indicates significant $(\mathrm{p}<0.01)$ mean difference from the control, ${ }^{\mathrm{b}}$ Numerical figures of the above table indicate mean \pm standard error.

Table 2 demonstrates that heart weight of rats of groups A, B and C increased insignificantly (p $>0.05)$ as compared to control. A significantly $(\mathrm{p}<0.01)$ higher liver weight was obtained in groups $\mathrm{B}$ and $\mathrm{C}$ than that of control. The liver weight also increased for group A but the difference was insignificant to that of control. No significant $(p>0.05)$ difference in the kidney weight was observed among the groups. However, the lowest mean of the kidney weight was recorded in the group A. Gaiva et al. (2003) observed that the liver weights of rats increase in fish oil, and soybean-fish oil treated groups. In the present investigation, the trend of increase of liver weight in rat was detected in soybean oil group followed by fish fat treated group that did not correspond with the findings of Gaiva et al. (2003). Similar variable results and no increase of organ weight were also described when rats were fed with combination of different fats and oils in different groups (Al-Othman, 2000). 
The present experiment reveals that edible beef fat, fish fat and soybean oil exerted no significant ( $\mathrm{p}>0.05$ ) effect on the body weight gain of the rats compared to control. It could be concluded that fats and oils are harmful for the rat's body especially on liver and heart. Decrease in kidney weight after feeding beef fat is really unknown. Beef fat might have some deleterious effect on kidney which may be confirmed by further kidney function test and histopathological examinations. However, a further study might be conducted with a greater number of rats and longer duration before making any conclusion about the effects of edible fats and oils.

\section{REFERENCES}

1. Al-Othman AA (2000). Growth and lipid metabolism responses in rats fed different dietary fat sources. International Journal of Food Sciences and Nutrition 51 (3): 159-167.

2. Barek MA, Ahmad N, Majumder S, Islam K and Islam R (2003). Hemato-biochemical parameters and performances of broiler feed with soybean oil and protein supplementation. Bangladesh Journal of Animal Science 32 (1): 131-138.

3. Baron BR and Browner WS (1998). Lipid abnormalities. In: Current Medical Diagnosis and Treatment. $37^{\text {th }}$ edn., Prentice Hall, New Jersey.

4. Gaiva MH, Gouto RC, Oyama LM, Couto GEC, Silveira VLF, Ribeiro EB and Nascimento CMO (2003). Diets rich in polyunsaturated fatty acids: effect on hepatic metabolism in rats. Nutrition 19 (2): 144-149.

5. Gomez KA and Gomez AA (1984). Statistical Procedures for Agricultural research. 2nd edn., John Wiley and Sons, New York.

6. Hosain MZ, Ahmad N, Saha SK, Majumder S, Miah MA and Halim MA (2004). Effects of different edibles oils on hemato-biochemical profiles in rats. Journal of Animal and Veterinary Advances 3 (7): 463-465.

7. Islam K, Ahmad N, Majumder S, Islam R and Barek MA (2002). Effect of dietary supplementation of soybean oil on body weight and certain hemato-biochemical parameters in broilers birds. Bangladesh Veterinary Journal 36 (1-2): 1517.

8. Li Y, Jiang WC and Fang JD (1996). Effects of different dietary fat sources on white Roman geese. Poultry Abstract 23 (4):117.

9. Lichtenstein AH (1998). Trans fatty acids and blood lipid levels, Lp (A), parameters of cholesterol metabolism, and hemostatic factors. Journal of Nutritional Biochemistry 9 (5): 244-248.

10. Rashid MH, Naser MA, Reza MM, Chowdhury BL and Gheyasuddin S (1998). Changes in the characteristics of fats and oils on cooking and their effects on the growth performance of rats. Bangladesh Veterinary Journal 32 (1-2): 96-103.

11. Saha SK, Ahmad N, Majumder S, Hosain MZ and Miah MA (2005). Effects of different edible oils on growth performance, different organ weight and serum transaminases in rats. Bangladesh Journal of Veterinary Medicine 3 (1): 79-81.

12. Slater TF (1972). Free Radical Mechanisms in Tissue Injury. Pion Ltd., London.

13. Steel RGD and Torrie JH (1980). Principles and Procedures of Statistics: A Biometrical Approach. $2^{\text {nd }}$ edn., McGraw Hill, New York. 